\title{
Fruticultura Tropical no Acre: implantação e resultados preliminares
}

Peter Weigel ('); Warwick Estevam Kerr $\left({ }^{3}\right)$; Noeli Pa ulo Fernandes (1); Humberto A. de Sousa e Silva ( $\left.{ }^{4}\right)$; Francisco Antonio de Oliveira Pita $\left({ }^{2}\right)$; Maria Helena de Araújo ( ${ }^{4}$ ).

\section{INTRODUÇÃO}

Em 1978, pelo Convênio INPA/Banco do Estado do Acre (BANACRE), foi iniciado o presente projeto, cujos principais objetivos são

testar e difundir algumas espécies de frutíferas nas vizinhanças de Rio Branco, Acre. Paralelamente, servirá para testar um método de rea-

(") - Este trabalho recebeu auxilio do POLAMAZONIA, BANACRE e CNPq.

(1) - Instituto Nacional de Pesquisas da Amazônia, Manaus

(2) - Instituto Nacional de Pesquisas da Amazônia, Acre

(3) - Faculdade de Medicina de Ribeirão Preto

(4) - Banco do Estado do Acre 
lizar experimentos em fazendolas particulares e verificar se serve para fixar o homem no campo.

A cidade de Rio Branco tem cerca de 120.000 habitantes e as frutas tropicais encontradas no Mercado Municipal săo raras e caras. limitando-se: a graviola, jaca, banana, tucumã, cupuaçu, cacau, açaí e, ainda mais raramente, patauá e bacaba. O projeto tem as seguintes caracteristicas principais: a) foi implantado, preferencialmente, em pequenos proprietários, que residissem em suas fazendas ou sítios; b) utilizaram-se apenas frutas tropicais regionais, especialmente aquelas mais em falta na área; c) foi implantado em áreas de capoeira, procurando promover uma utilização racional destas áreas, normalmente abandonadas por 5 anos ou mais, depois de 1-2 anos de plantio, após o desmatamento. Com o plantio em sítios de pequenos proprietários pensou-se em: a) evitar a compra de terra para o projeto; b) dar uma ampliação social à pesquisa, visto que, ao seu término, em 1988, teriam sido tomados os dados programados, selecionadas as melhores plantas para a região e, os proprietários ficariam com $\alpha$ pomar formado e as respectivas técnicas.

\section{MATERIAL}

Para implantação do projeto, foram escoIhidas as espécies frutiferas abaixo relacionadas, que foram coletadas em diferentes regiões da Amazônia, uma vez, que, em certas regiōes, estas espécies apresentam variedades excep. cionais quanto ao tamanho e ao peso do frutc, sabor e rendimento. Nas descrições abaixo, será usada a palavra vinho no sentido do norte: suco ou vitamina, ao qual se adiciona açucar ou farinha de mandioca, conforme o gosto.

1. Annona muricata L. (Graviola). Árvore de porte pequeno a mediano $(4-8 \mathrm{~m})$, produz frutos de cor verde, com polpa branca, sucosa, agridoce, de cheiro e sabor muito agradáveis. com peso variando entre 250-2700 gramas. Utilizada em forma de sorvete ou ao natural, com ou sem açucar. Começa a frutificar de 3 anos em diante. Foi coletada em Belém (PA), por Peter Weigel e Noeli P. Fernandes.
2. Rollinia mucosa (Jacq.) Baill. (R. orthopetala A. DC. Annona mucosa Jacq.) (Biribá). Árvore de porte médio $(6-10 \mathrm{~m})$, fruto amarelado, polpa abundante e sucosa, de sabor adocicado e agradável, com peso até 1.350 gramas. Inicia a frutificação após 4 anos e é consumida apenas ao natural. Foi coletada em Belém (PA), por Peter Weigel e Noeli P. Fernandes.

3. Quararibea cordata (Humb. \& Bonpl.) Vischer = Matısia cordata (H.B.K.) (Sapota). No estado selvagem, em mata virgem, cresce até $40-45 \mathrm{~m}$, porém quando cultivada atinge apenas cerca de $10-15 \mathrm{~m}$. Produz um fruto verde castanho, com peso variando entre $300-1200$ gramas, com polpa amarelo-alaranjada, de saber açucarado, bastante agradável. Começa a frutificar por volta de 7-8 anos. Consumida ao natural e coletada em Tefé (AM) por Danilo F. da Silva e Warwick E. Kerr.

4. Artocarpus incisa L. (Fruta-pão). Atinge a altura de $25-30 \mathrm{~m}$, com o fruto podendo atingir até $4 \mathrm{~kg}$. No projeto foi utilizada a variedade seminifera (com sementes), conhecida como "fruta-pão-de-caroço". Contém em média 60 sementes, as quais cozidas, tem sabor similar ao da castanha européia (Castanea sativa). Começa a frutificar aos 5 anos. Foi coletada em Belém (PA) e Manacapuru (AM), por Peter e Noeli P. Fernandes.

5. Pourouma cecropiaefolia Mart. (Mapati, Purumã, Cucura). Árvore em tudo semelhante às imbaúbas. O fruto é uma drupa ovato-globosa, de cor atro-purpúrea, ou mesmo preta, com polpa mucilaginosa doce, acidulada, que envolve um único caroço. Começa a frutificar aos 4 anos. Consumida ao natural fornecendo também um vinho excelente e foi coletada em Benjamin Constant (AM) e Letícia (Colombia), por Danilo F. da Silva.

6. Euterpe oleracea Mart. e Euterpe precatoria Mart. (Açaí). Atinge, em média 15-20m de altura, tendo crescimento em touceiras ou em pés simples, conforme a espécie. $O$ número de cachos por pé varia até 8 , sendo mais comum de 3-4 tendo cada cacho peso de $5-6 \mathrm{~kg}$. Seu consumo é na forma de vinho, a partir do qual é feito, também, sorvete. Começa a frutificar aos 5-7 anos e foi coletado em Manaus (AM), por Peter Weigel e Noeli P. Fernandes. 
7. Bactris gasipaes (HBK) $=$ Guilielma gasipaes (H.B.K.) Bailey (Pupunha). Atinge até $20 \mathrm{~m}$ de altura, tendo crescimento em touceiras, com troncos geralmente revestidos por espinhos finos e penetrantes. O número de inflorescências por pé, varia, podendo chegar até 10 . Os cachos pesam, em média, $3-5 \mathrm{~kg}$. Após cozida com sal, mantém elevado teor em vitamina $A$, e pode ser consumida com mel. café ou em forma de doces, vinhos, etc. Começa a frutificar aos 3-4 anos. Foi coletada em Benjamin Constant (AM), por Danilo F. da Silva e Warwick E. Kerr.

8. Manilkara zapota (L.) P. van Royen = Acharas sapota L. (Sapoti). Árvore de altura mediana $(6-10 \mathrm{~m})$, fruto com polpa suculenta e doce, de sabor e cheiro agradáveis, com peso de 250-500 gramas. Consumida geralmente, ao natural ou em forma de sorvete. Começa a frutificar aos 5-6 anos e foi coletada em Farintins (AM) e Belém (PA), por Peter Weigel, Noeli P. Fernandes e Danilo F: da Silva.

9. Pouteria caimito (Ruiz \& Pav.) Radlk (Abiu). Árvore pequena com $4 \mathrm{~m}$ de altura, podendo porém alcançar até $10 \mathrm{~m}$. Frutos com polpa brancacenta de consistência gelatinosa e sabor adocicado, com peso variando de 200-1500 gramas. É consumida ao natural. Começa a frutificar aos 3 anos. Foi coletada em Benjamin Constant (AM), por Danilo F. da Silva.

10. Theobroma grandiflorum (Willd ex Spreng) Schum (Cupuaçu). Em estado selvagem, ultrapassa os $20 \mathrm{~m}$ de altura, porém, quando cultivado, o porte varia de $6-10 \mathrm{~m}$. O fruto pesa até 1500 gramas, com casca dura e lenhosa, polpa (comestível) amarelada ou brancacenta, abundante, de sabor ácido e cheiro forte, agradáveis. Com a polpa preparam-se sorvetes, vinhos, licores e compotas. Começa a frutificar aos 3-4 anos. Foi coletada em Santarém (PA), Belém (PA), e Manaus (AM), por Peter Weigel, Noeli P. Fernandes e Danilo F. da Silva.

Mais informações sobre estas espécies podem ser obtidas na publicação de Clement et al. (s/d).

\section{COLETA DE INFORMAÇões CIENTÍFICAS}

Para avaliação do comportamento das espécies frutíferas consideradas e para formação de um banco de informações, uma vez que existem poucas informações sobre estas espécies, será realizada uma série de determinações, nos seguintes parâmetros: $n^{\circ}$ de dias para germinaçäo, porcentagem de germinação, tamanho das mudas no plantio definitivo, época de florescimento, tempo até a $1^{\text {a }}$ produção, altura da planta ( $1^{\mathrm{a}}$ e $2^{\mathrm{a}}$ produção), diâmetro da copa ( $1^{\mathrm{a}}$ e $2^{\mathrm{f}}$ produção), $n^{\mathrm{o}}$ de frutos ( $1^{\mathrm{a}}$ e $2^{\mathrm{a}}$ produção), tamanho do fruto ( $1^{\text {a }}$ e $2^{\mathrm{a}}$ produção), circunferência do fruto ( $1^{\mathrm{a}}$ e $2^{\mathrm{a}}$ produção), peso do fruto $\left(1^{\mathrm{a}}\right.$ e $2^{\mathrm{a}}$ produção) e resistência às doenças e pragas.

Estas informações poderão servir, no futuro, como base para outros projetos semelhantes e para maior êxito de futuros experimentos. Os dados referentes a $n^{\circ}$ de dias para germinação e porcentagem de germinação de 1979 , foram perdidos nos primeiros canteiros face à assistência deficiente e grande rotatividade dos viveiros.

\section{ÁREAS PLANTADAS}

Em dezembro de 1979 a janeiro de 1980, foram implantadas as propriedades abaixo relacionadas.

1. Sr. Manoel Cícero dos Santos, 9 ha situados ao norte de Rio Branco, no Km 12 da Estrada Dias Martins, $\mathrm{Km} 3$ do Ramal Adauto Frota.

2. Dr. José Chagas de Souza, 7,5 ha situados ao norte de Rio Branco, no Km 28 da BR$364, \mathrm{Km} 6$ do Ramal Santa Luzia.

3. Sr. Dário Rodrigues Cruz, 9 ha situados ao norte de Rio Branco, na Colônia OlhoD'água, $\mathrm{Km} 3$ da Estrada Barro Vermelho.

4. Bonal Borracha Natural S.A., 9 ha situados ao sul de Rio Branco, Km 76 da BR-364.

5. Sr. Raimundo Soares Pessoa, 7,5 ha situados ao norte de Rio Branco, na Colônia Boa Vista, Km 27 da BR-364, Km 7 do Ramal Pontão. 
6. Sr. Adauto Carneiro Lima, 7,0 ha situados no Km 25 da Estrada do Quixadá, Seringal Quixadá - Fazenda Boa Água.

No quadro em anexo, encontram-se relacionados os proprietários, às espécies implantadas, área por espécie e tamanho médio das mudas/espécies na época do plantio.

\section{DIFICULDADES}

Serão relatadas aqui algumas dificuldades, com as quais devem contar pesquisadores que desejem fazer ciência distante dos grandes centros. Houve grande rotatividade de viveiros, sendo que em maio-junho 1979, as mudas estavam dispersas por três viveiros bastante distanciados entre sí, o que contribuiu significativamente para a falha na coleta de dados de germinaçäo. Finalmente, em julho/79 as mudas foram concentradas no viveiro da Secretaria de Desenvolvimento Agrário, no Município de Senador Guiomard, a $20 \mathrm{Km}$ de Rio Branco, tendo ocorrido perdas significativas de material durante o transporte. Muito prejudicial, também, foi a grande falta de infra-estrutura de Rio Branco com significativa falta de defensivos, os quais precisaram ser adquiridos em Manaus e outras regiões do país e, posterior- mente, enviados a Rio Branco. Assim, ocorreram perdas de mudas por falta de tratamento fitossanitários imediato, como no caso da frutapão, que apresentou alto ataque de nematóides (Meloidogyne thamesi (Chitwood, 1952) Goodery, 1963). As mudas de biribá apresentaram forte ataque de Fusarium solani (Mart.) Appel \& Wn., chegando a morrer 2400 mudas, o que se deveu à falta de tratamento do solo destinado às sementeiras e aos sacos plásticos. pela produção de mudas. As mudas de mapati e abiu apresentaram problemas até agora näo solucionados, tendo sido perdidas quase todas as mudas, sendo que, no caso do abiu, parece ser uma virose.

\section{Estado atuaL}

Foram implantados apenas 49 ha em 6 ha em propriedades, ao invés de 100 ha em 10 propriedades. Entretanto, as mudas instaladas no campo estão tendo desenvolvimento e adaptação excelentes. Está em andamento nova coleta de sementes, para completar a área restante e para reposição de plantas mortas nas propriedades já implantadas. Foi firmado um acordo entre o INPA e a Universidade Federal do Acre (UFAC), ficando esta responsável

\begin{tabular}{|c|c|c|c|c|c|c|c|c|c|c|c|c|}
\hline \multirow[b]{2}{*}{ ESPECIES (ha) } & \multicolumn{2}{|c|}{$\begin{array}{l}\text { MANOEL } \\
\text { CICERO } \\
\text { DOS SANTOS }\end{array}$} & \multicolumn{2}{|c|}{$\begin{array}{c}\text { JOSE } \\
\text { CHAGAS } \\
\text { DE SOUZA }\end{array}$} & \multicolumn{2}{|c|}{$\begin{array}{l}\text { DARIO } \\
\text { RODRIGUES } \\
\text { CRUZ }\end{array}$} & \multicolumn{2}{|c|}{ BONAL S/A. } & \multicolumn{2}{|c|}{$\begin{array}{l}\text { RAIMUNDO } \\
\text { SOARES } \\
\text { PESSOA }\end{array}$} & \multicolumn{2}{|c|}{$\begin{array}{l}\text { ADAUTO } \\
\text { CARNEIRO } \\
\text { LIMA }\end{array}$} \\
\hline & $\begin{array}{l}\text { Área } \\
\text { (ha) }\end{array}$ & $\hat{\mathrm{H}}(\mathrm{cm})$ & $\begin{array}{l}\text { Área } \\
\text { (ha) }\end{array}$ & $\hat{\mathrm{H}}(\mathbf{c m})$ & $\begin{array}{l}\text { Área } \\
\text { (ha) }\end{array}$ & $\hat{\mathrm{H}}(\mathrm{cm})$ & $\begin{array}{l}\text { Área } \\
\text { (ho) }\end{array}$ & $\hat{\mathrm{H}}(\mathrm{cm})$ & $\begin{array}{l}\text { Área } \\
\text { (ha) }\end{array}$ & $\hat{H}(\mathrm{~cm})$ & $\begin{array}{l}\text { Área } \\
\text { (ha) }\end{array}$ & $\hat{H}(\mathrm{~cm})$ \\
\hline ABIU & 1,0 & 43,84 & - & - & 1.0 & 59,43 & - & 一 & - & - & - & - \\
\hline AÇAI & 0,5 & 11.16 & - & - & 0,5 & 11,65 & - & - & - & - & - & - \\
\hline BIRIBA & 1,0 & 50,64 & 1,5 & 54,03 & 1,0 & 52,63 & 3.0 & 49,20 & 1,5 & 60,06 & 1.5 & $(*)$ \\
\hline CUPUAÇU & 1.15 & 31,16 & 1,5 & 54.03 & 1,15 & 44,03 & - & - & 1,5 & 39,33 & 1,5 & $(*)$ \\
\hline GRAVIOLA & 1,15 & 34,85 & 1,5 & 49.46 & 1,15 & 47,53 & 3,0 & 53.80 & 1,5 & 52,00 & 1,5 & $(*)$ \\
\hline MAPATI & 0,2 & 24,48 & - & - & 0,2 & 22,51 & $\rightarrow$ & - & - & - & - & - \\
\hline PUPUNHA & 1,0 & 44.40 & 1,5 & 39,20 & 1,0 & 59,43 & 2,0 & 29.95 & 1,5 & 45,93 & 1,5 & $\left({ }^{\circ}\right)$ \\
\hline SAPOTA & 1,5 & 26,44 & - & - & 1.5 & 14,53 & - & - & - & - & - & $\rightarrow$ \\
\hline SAPOTI & 1.5 & 8,15 & 1,5 & 11.50 & 1,5 & 7,23 & 1,0 & 10,00 & 1,5 & 13,46 & 1,0 & $\left({ }^{\circ}\right)$ \\
\hline FRUTA.PĀO & - & - & - & - & - & - & - & - & - & 一 & - & - \\
\hline TOTAL & 9.0 & & 7,5 & & 9,0 & & 9,0 & & 7,5 & & 7.0 & \\
\hline
\end{tabular}

$\widehat{H}=$ tamanho niédio das mudas

(*) Todas as mudas morreram por falta de chuvas. 
pela produção de mudas para o segundo plantio. Como conseqüências impcrtantes do projeto, até o momento, podem ser apontadas: a) A instalação, quando do início da produção, de uma agroindústria para fabricação de sucos, compotas e doces com as frutas do projeto; b) fabricação de iogurte com sabor de frutas tropicais pela Companhia Industrial de Laticínios do Acre (CILA).

\section{SUMMARY}

In Rio Branco, Acre, by the convention INPA/ BANACRE, was started in 1978 the installation of a project of tropical fruit culture. There were selected 10 small scale farmers with low income and were selected also the follewing fruit species: Annona muricata L., Rollinia mucosa (Jacq.) Baill., Matisia cordata $($ H.B.K.) = Quararibea cordata (Humb. \& Bonpl.) Vischer, Arthocarpus incisa L., Pourouma cecropiaefolia Mart., Euterpe oleracea Mart., Bactris gasipaes
H.B.K. = Guilielma gasipaes (H.B.K.) Bailey, Achras sapota L. = Manilkara zapota (L.) van Royen, Pouteria caimito (Ruiz \& Pav.) Radlk and Theobroma grandiflorum (Willd \& Spreng) Schum. These species were collected in several regions in the Amazon basin. There is being made a constant evaluation of several characters to form an information bank and to evaluate the adaptation of the species. In the period of November/78 to February $/ 80$, were planted 49 ha on 6 properties, and until March/81 there will be planted more $51 \mathrm{ha}$, to reach the ideal of 10 ha 10 properties (100 ha).

\section{REFERÊNCIAS BIBLIOGRÁFICAS}

Clement, C.R.; Kerr, W.E.; Weber, A.; Freitas Jr., E.; Arkcoll, D.B.; Ranzani, G.; Pahlen, E. von der s/d - Ecologia e Fruticultura na Amazônia. In: 1. Encontro Nacional de Fruticultura Tropical. (no prelo).

(Aceito para publicação em 11/09/80) 